\title{
EVALUATION OF HEALTHCARE \\ PROFESSIONALS' KNOWLEDGE ON CODE BLUE: A MULTI-CENTRE SURVEY STUDY
}

\section{Abstract}

Introduction: The Blue Code practice provides increase in survival rates and decrease in the rate of permanent sequelae after cardiac arrest. There are issues that healthcare workers should pay attention to in the Code Blue practice.

\section{Aim}

The primary purpose of this survey study is to determine the knowledge levels of physicians and nurses about the Code Blue and cardiopulmonary resuscitation in 6 centres. The secondary aim is to determine the solutions that can be made to eliminate these deficiencies.

\section{Methods}

After the approval of the Faculty Ethics Committee, Mersin University Faculty of Medicine, Adana Baskent Turgut Noyan Training and Research Hospital, Dokuz Eylül Univ. Faculty of Medicine, Hacettepe University Faculty of Medicine, Gulhane Training and Research Hospital, Manisa Celal Bayar Univ. Faculty of Medicine, except for the doctors and technicians of the Department of Anaesthesiology and Reanimation and the healthcare professionals working in the intensive care units, the doctors and nurses working in other departments were asked to answer the questions in the questionnaire via the internet with the questionnaire form stated in Appendix 1.

\section{Results}

A total of 415 participants responded the survey. Of them, $45.8 \%$ were nurses, $24.8 \%$ residents, $23.3 \%$ faculty members, $5.4 \%$ specialist doctors and $0.7 \%$ general practitioners. Totally $86.6 \%$ of the participants knew the Code Blue number. To the question "What is the Code Blue?", $92.7 \%$ of the participants gave the correct answer to his question. „Do you hesitate to intervene when you encounter a patient requiring emergency intervention?" $25.9 \%$ of the participants answered "Yes" to the question. "Is there a form about Code Blue in your clinic?" $41 \%$ answered "No" to the question.

\section{Conclusion}

According to the results of the survey we conducted, we are of the opinion that healthcare workers have insufficient knowledge about the Code Blue. In order to solve these problems, it would be appropriate to direct healthcare professionals to both in-hospital and external training programs.

\section{USTANOVA}

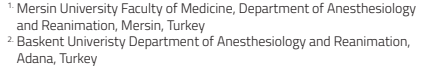

Adana, TUrkey
Celal Bayar University Faculty of Medicine, Department of Anesthesiologg and Reanimation, Manisia, Turkey - Dokuz Eylul University Faculty of Medicine, Dey
Anesthesiology and Reanimation Izmir Turbey Anesthesiology and Reanimation, Izmir, Turkey
5 Hacettepe University fauculty of Medicine, Depart
Anesthesiology and Reanimation, Ankara, Turkey MD, Associate Professor, Gulhane Training and Research Hospita,
Department of Anesthesiology and Reanimation, Ankara, Turke

\section{AUTOR ZA} KORESPODENCIJU:

Aslinur SAGUN

E-mail:aslinur_aslan@hotmail.com
KLUČNE REČl:

\section{KEY WORDS:}

Code Blue, healthcare worker, education, resuscitation
DATUM PRIJEMA RADa

25.03.2021

DaTUM PRIHUATANJA RADa

20.05.2021.

Datum Objayluivanua 


\section{Introduction}

Code Blue (CB) is a unique worldwide code used to caIl code team for deteriorating or cardiac arrest patients in hospital [1]. The victims can be in-service patients, relatives of the patients, hospital staff or others. Although the call numbers may differ between countries, the number in our country is 2222 .

The resuscitation team members should be trained for basic and/or advanced life support and, ideally there should be a doctor, an anaesthesia technician or a nurse, in our country due to the legal legislations also a paramedic staff and a security guard should be in the team [2].

The survival of the patient is strictly dependent on the time elapsed between the cardiac arrest to resuscitation and it's estimated to be 3-5 minutes [3]. In addition, until the team arrives, if possible, the person calling the CB should begin basic life support skill.

The resuscitation equipments and specific drugs are in the emergency box with the team but they also have to be in all wards and specific places in the hospital. The knowledge of the healthcare professionals and hospital staff about CB and emergency situations should be basically adequate, if not, it has to be improved by trainings. For the purpose to evaluate the knowledge of the healthcare professionals about CB and cardiopulmonary resuscitation (CPR), we conducted this survey in six central hospitals. According to the results of this survey, actual courses or education programmes can be organised and the level of knowledge and awareness about CB can be increased.

\section{Method and Materials}

After the approval of local ethics committee in Mersin University Faculty of Medicine, Clinical Trials Ethics Committee (Number: 78017789/050.01.04/1075579), the survey was sent to responsible researchers of Departments of Anesthesiology and Reanimation of five hospitals (Adana Baskent University Hospital Dokuz Eylul University Faculty of Medicine, Hacettepe University Faculty of Medicine, Gulhane Training and Research Hospital, Manisa Celal Bayar University Faculty of Medicine). A questionnaire consisting of 21 questions was prepared (Appendices 1). . First 4 questions are about personal information, other 17 questions are about CB. All the questions are multi-choice and the time required for answering the questions is about 5 minutes. The data was collected between August and October 2019. The survey was conducted to healthcare professionals (doctors and nurses) except anaesthetists, anaesthesia technicians, the doctors and nurses of intensive care unit (ICU) and Emergency Service on the internet (https://docs.google.com/forms/u/1/d/1nZGDE7/91DnglB7HIxF50u3rvpe8X5WIbgiLWR8e5w8/edit?usp=forms _home\&ths=true ) .

\section{Results}

The survey was conducted with 1600 healthcare professionals in 6 hospitals. But totally 415 (25.9\%) participants responded the survey. The participants did not respond every question, some of the questions were not ticked.

Personal informations about the participants (first four questions) are shown in Table 1.

Table 2 shows the responds of questions 5, 6, 7, 8 and 9.

Question number 10 was asking true sentences about $\mathrm{CB}$ and there was 6 options, only 2 of them were wrong. Totally 402 (96.8) participants responded this question. Only $6.4 \%(n=26)$ of them marked as wrong, the rest of the participants responded truly.

The eleventh question is "In which of the following situations should Code Blue be called?". Totally 406 participants replied this question and it's a multiple-choice one. The vast majority of the participants ( $n=391$, 96.3\%) marked "Respiratory arrest patient", secondly they marked "Pulseless patient" ( $n=386,95.1 \%)$, "Unconscious patient" ( $n=212,52.2 \%)$, "Patient with decreased oxygen saturation" ( $n=57,14 \%$ ), "Fainted patient" ( $n=36,8.9 \%)$, "Patient with low blood pressure or pulse" ( $n=20,4.9 \%)$, "The relative of intensive care patient relapses after crying in the waiting area whose and whose breathing and pulse are present" ( $n=5$, $1.2 \%$ ) respectively. Nobody marked "Vomiting patient" option at this question.

The other question was "Who gives the Code Blue caII?" and there were 5 choices. Most of the answers were "Doctors" ( $n=383,94.3 \%)$ and "Nurses" $(n=382,94.1 \%)$. In consecutive, "Personnel" ( $n=186,45.8 \%)$, "Security staff" ( $n=146,36 \%)$, "Secretary" ( $n=143,35.2 \%)$ were the answers.

Table 3 shows the distribution of questions about BLS and ALS.

The following question was "If you had BLS education, when?" and totally 359 participants replied. The majority of the participants $(n=238,66.3 \%)$ marked "In the last 5 years", respectively "In between 5 and 10 years ago" $(n=74,20.6 \%)$, "More than 10 years ago" $(n=47,13.1 \%)$. The next question was "If you had ALS education, when?" and there were 248 answers. The majority of the participants $(n=168,67.7 \%)$ marked "In the last 5 years", respectively "In between 5 and 10 years ago" 
Table 1. Distribution of Personal Informations of the Participants

\begin{tabular}{|c|c|c|}
\hline Personal Information & $\mathbf{n}$ & $\%$ \\
\hline \multicolumn{3}{|l|}{ Profession } \\
\hline Faculty member & 94 & 23.3 \\
\hline Specialist & 22 & 5.4 \\
\hline Medical practitioner & 3 & 0.7 \\
\hline Resident & 100 & 24.8 \\
\hline Nurse & 185 & 45.8 \\
\hline Total & 404 & \\
\hline \multicolumn{3}{|l|}{ Institution } \\
\hline University hospital & 329 & 81.6 \\
\hline Foundation university & 2 & 0.5 \\
\hline $\begin{array}{l}\text { Training and Research Hospital } \\
\text { Other }\end{array}$ & 68 & 16.9 \\
\hline Total & 4 & 1 \\
\hline Department & 403 & \\
\hline Surgical & & 50.7 \\
\hline Internal & 204 & 29.9 \\
\hline Other & 120 & 19.4 \\
\hline Total & 78 & \\
\hline Professional Experience & 402 & \\
\hline \multicolumn{3}{|l|}{ 0-1 year } \\
\hline $1-5$ years & 29 & 7.2 \\
\hline $5-10$ years & 111 & 27.4 \\
\hline$>10$ years & 66 & 16.3 \\
\hline \multirow[t]{2}{*}{ Total } & 199 & 49.1 \\
\hline & 405 & \\
\hline
\end{tabular}

$(n=55,22.2 \%)$, "More than 10 years ago" $(n=25,10.1 \%)$. Table 4 shows the answers of last five questions.

\section{Discussion}

Although all of the participants were healthcare professionals, it was concluded that they did not have enough information about CB and CPR in line with the answers given. Even though the CB call number is a nationally used one, it was observed that not all participants gave the correct answer to this question.

The vast majority of the participants knew what the CB is. Only six participants answered this question incorrectly. Another question about who must be in the CB team was answered by half of the participants correctly but a knowledge gap or confusion about this issue was noticed. Almost every participants marked doctor and nurse, ideally there must be a personnel and an anae-

Table 3. The distributions of answers of questions about BLS and ALS

\begin{tabular}{llll}
\hline Questions & \multicolumn{1}{c}{ Yes } & No & \multicolumn{1}{c}{ Total } \\
$\mathbf{n}$ & $\mathbf{n}$ & $\mathbf{n}$ \\
\hline $\begin{array}{l}\text { Have you ever take an edu- } \\
\text { cation about Basic Life Sup- } \\
\text { port (BLS)? }\end{array}$ & $354(87.8 \%)$ & $49(12.2 \%)$ & 403 \\
\hline $\begin{array}{l}\text { Have you ever take an edu- } \\
\text { cation about Advanced Life } \\
\begin{array}{l}\text { Support (ALS)? } \\
\hline\end{array}\end{array}$ & & \\
\hline
\end{tabular}

Table 2. Responds of Question 5,6,7,8 and 9

\begin{tabular}{|c|c|c|c|}
\hline Questions & $\begin{array}{c}\text { True } \\
\mathbf{n}\end{array}$ & $\begin{array}{l}\text { False } \\
\mathrm{n}\end{array}$ & $\begin{array}{c}\text { Total } \\
\mathbf{n}\end{array}$ \\
\hline What's the Code Blue number? & 342 & 53 & 395 \\
\hline What's the Code Blue?* & 401 & 6 & 404 \\
\hline $\begin{array}{l}\text { Who should be in the Code Blue } \\
\text { team?* }\end{array}$ & 124 & 281 & 405 \\
\hline $\begin{array}{l}\text { What is the maximum time of the } \\
\text { Code Blue team to arrive the vic- } \\
\text { tim?* }\end{array}$ & 198 & 201 & 399 \\
\hline $\begin{array}{l}\text { Where must be the Code Blue } \\
\text { emergency equipment? }\end{array}$ & 300 & 105 & 405 \\
\hline
\end{tabular}

* Multiple options can be marked in these questions.

sthesia technician in the team.

In several studies it's showed that the initial time of CPR, means early intervention and defibrillation, is very important for survival $[4,5]$. Every minute in cardiac arrest is valuable. It is found more successful to start CPR in 1.5-2 minutes than in more than 5 minutes [6]. When the maximum time for the $\mathrm{CB}$ team to arrive at the scene was asked, most of the participants answered this question correctly but not all of them. So, this result showed that there should be trainings not only about the cardiopulmonary resuscitation but also general framework of CB implementation.

In-hospital cardiac arrests, the equipments or drugs are used by the practitioners and CB team. And ideally, all the supplies of emergency situation have to be in both code blue CB team and wards [7]. There was a question about the place where the equipments should be, very few patients marked as in both CB team and in the wards. The majority of the respondents thought that they should be in all the services.

The healthcare worker detecting CB is responsible for providing $B L S$ to increase the rate of survival until the team arrive [8]. For this purpose, there is a legislation by Ministry of Health in our country, every health worker has to receive training on $B L S$ once a year. The CB team take information about the patient if available and then take over the resuscitation [9]. Most of the participants but not all of them, knew that staff who detected Code Blue is responsible for providing basic life support until the blue code team arrives. In this survey, very few of the participants marked "The only task of the Code Blue team is to provide the patient's airway (intubation)". Some of the healthcare workers think that only endotracheal intubation is the procedure that cannot be performed by other staff except anaesthetists. Most of the participants marked "Before making 
Table 4. Distribution of answers of five questions

\begin{tabular}{llll}
\hline Questions & Yes & No & Total \\
& $\mathbf{n , ~ ( \% )}$ & $\mathbf{n},(\%)$ & 389 \\
\hline Do you follow the resuscitation guidelines? & $302,(77.6)$ & $297(74.1)$ & 401 \\
\hline $\begin{array}{l}\text { Do you hesitate to intervene when you encounter a patient } \\
\text { who needs emergent intervention? }\end{array}$ & $104(25.9)$ & $86(46.3)$ & 402 \\
\hline $\begin{array}{l}\text { Do you feel sufficient about knowledge and practice? } \\
\text { Do you have a form in your clinic regarding the Code Blue? }\end{array}$ & $230(59)$ & $160(41)$ & 390 \\
\hline Is there an algorithm for the Code Blue in your institution? & $307(78.1)$ & $86(21.9)$ & 393 \\
\hline
\end{tabular}

a Code Blue call, the patient's airway, breathing, circulation (ABC) and consciousness status should be checked and if any of them have a problem, a Code Blue call should be made." But almost a quarter of the participants did not think so. The minority of the participants thought that nothing should be done until the team arrives. It's not acceptable that a health worker doing nothing in a cardiac arrest patient.

The record of the resuscitation procedure is necessary for several reasons such as collecting data, controlling the procedure and legal aspects. There is a Code Blue Notification Form in every hospital in Turkey. In addition to this form, hospitals may use their own form for archive. This form should be filled completely by the team leader. In this survey, lack of knowledge about this form was found.

Ethically, if the CB is called for an in-patient, the responsible doctor of the patient should be informed [10]. However, three quarters of the participants agreed with this, rest of them thought that it's unnecessary to inform the responsible doctor.

It's suggested to call CB in adults immediately for any patient who's unresponsive, apneic, and/or pulseless. But, in some cases, it should be called for deteriorating patient. The answers of the question related to this issue was marked as CB team should be called for pulseless and apneic patients. In fact, a confusion about in which patients CB team should be called was detected. There can be local protocols for summoning CB team depending on hospital policies; all staff should call the team in their institute. According to the survey findings, the participants thought the call should be given by doctors or nurses.

Basic Life Support training is very essential for hospital staff. Their knowledge and performance can improve patients outcomes [9]. Also continuation of education is very important actually. It's suggested to repeat BLS trainings at every two years. Education programs of institutes varies. In our hospital it is compulsory to give this training to every new nurse who comes to the hos- pital, schedules are prepared by head nurse responsible for education. Most of the participants had BLS educations, but the ratio of staff taking this education within five years is not sufficient. The number of participants taking Advanced Life Support training is lower than BLS. The guidelines for resuscitation eliminate chaos in cardiopulmonary arrest scene, prevent unnecessary applications. Unfortunately a quarter of the participants did not implement the guidelines. At about half of the participants feel themselves insufficient in CPR. It is an important problem for health system of the country.

\section{Conclusion}

There are serious problems about CB and CPR practices.

- Training programmes about legal aspects of CB should be arranged.

- Who should call the team? For which patients, the CB team should be called? When the team should be at the scene? These questions should be taught to healthcare workers and the staff.

- Basic Life Support training should be done effectively, preferably with small groups (The staff can be classified into two or three groups according to number in each department). And also it's very important to provide the continuation of the trainings.

- Advanced Life Support trainings should be increased and the staff working in risky places should be provided with this training.

- In institutes, it's better to have algorithms and notification forms to prevent chaos and collect healthy data.

In conclusion, according to the results of the survey conducted, it's considered that healthcare workers have insufficient knowledge of the Code Blue. In order to solve this problem, it would be appropriate to direct healthcare professionals to both in-hospital and/or external training programs.

\section{Conflict of Interest:}

None 


\section{References}

1. Risaliti C, Evans K, Buehler J, Besecker B \& Ali N. Decoding Code Blue: A process to assess and improve code team function (2018). Resuscitation. Jan;122:e15-e16. DOI: 10.1016/j.resuscitation.2017.11.039

2. Porter, J. E., Lecturer, S., Mcnabb, T. J., Hon, B. N., \& Missen, K. (2019). A review of Code Blue activations in a single Regional Australian Healthcare Service : A retrospective descriptive study of RISKMAN data. June, 221-227. https://doi.org/10.1111/jocn. 15079

3. Honarmand K, Mepham C, Ainsworth C \& Khalid Z (2018). Adherence to advanced cardiovascular life support (ACLS) guidelines during in-hospital cardiac arrest is associated with improved outcomes. Resuscitation. Aug;129:76-81. DOI: 10.1016/j.resuscitation.2018.06.005.

4. Barbosa, V., Gomes, E., Vaz, S., Azevedo, G., Fernandes, G., Ferreira, A., \& Araujo, R. (2016). Failure to activate the in-hospital emergency team: Causes and outcomes. Revista Brasileira de Terapia Intensiva, 28(4), 420-426. https://doi.org/10.5935/0103-507X.20160075

5. Craig-Brangan KJ \& Day MP (2019). Update: 2017/2018 AHA BLS, ACLS, and PALS guidelines. Nursing. Feb;49(2):46-49. DOI: 10.1097/01.NURSE.0000552705.65749.a0.
6. Menon VP, Prasanna P, Edathadathil F, Balachandran S, Moni M, Sathyapalan D, Pai RD \& Singh S (2018). A Quality Improvement Initiative to Reduce „Out-of-ICU" Cardiopulmonary Arrests in a Tertiary Care Hospital in India: A 2-Year Learning Experience. Quality Management in Health Care. Jan/Mar;27(1):39-49. DOI: 10.1097/QMH.0000000000000160.

7. Lockey A, Lin Y \& Cheng A (2018). Impact of adult advanced cardiac life support course participation on patient outcomes-A systematic review and meta-analysis. Resuscitation. Aug;129:4854. DOI: 10.1016/j.resuscitation.2018.05.034.

8. Jackson J E \& Grugan A S (2015). Code blue: do you know what to do? Nursing. May;45(5):34-9; quiz 39-40. DOI: 10.1097/01. NURSE.0000463651.10166.db.

9. Spitzer CR, Evans K, Buehler J, Ali N \& Besecker BY (2019). Code blue pit crew model: A novel approach to in-hospital cardiac arrest resuscitation. Resuscitation. Oct;143:158-164. DOI: 10.1016/j.resuscitation.2019.06.290.

10. Ozmete $O$ (2017). Results of a blue code implementation at a university hospital. Cukurova Medical Journal. 42(3):446-450. DOI: 10.17826/cutf.3233919. 